\title{
Gender Difference in Cisplatin-Induced Nephrotoxicity in a Rat Model
}

\author{
Amr Ahmed EL-Arabey ${ }^{1, *}$ \\ ${ }^{1}$ Pharmacology and Toxicology Department, Faculty of Pharmacy, Al-Azhar University, Nasr City, Cairo, Egypt \\ ${ }^{*}$ Corresponding author: Amr Ahmed EL-Arabey, Pharmacology and Toxicology Department, Faculty of Pharmacy, Al-Azhar University, Nasr City, Cairo, Egypt. Tel: +20-1006180922, \\ E-mail:ph.amrcapa@gmail.com
}

Received: September 13, 2014; Accepted: October 4, 2014

Keywords:Cisplatin; Gender; Nephrotoxicity; Rat

\section{Dear Editor,}

In a published article entitled "Gender Difference in Cisplatin-Induced Nephrotoxicity in a Rat Model: Greater Intensity of Damage in Male than Female", The authors concluded that due to an unknown mechanism, cisplatin (CP)-induced nephrotoxicity depends on sex; they suggested that sex differences in renal circulation might be the key factor leading to this difference (1). The reason for these differences is not related to female sex hormones, because estrogen promotes CP-induced nephrotoxicity (2-4). Sex difference in renal circulation may be the reason for sex-related CP-induced nephrotoxicity. Simulation of angiotensin system receptors leads to different responses in the sexes $(5,6)$ with more vasodilator effects in female, which influences renal blood flow (RBF). On the other hand, the RBF is disturbed by $\mathrm{CP}$ (7). Therefore, the female RBF might be reduced less by CP than male's might be, which causes less damage (1). I would like to mention that new reason for these differences is related to CP uptake. The CP is cleared by the kidney through both glomerular filtration and tubular secretion (8). The concentrations of CP within the kidney exceed those in blood, suggesting an active accumulation of drug by renal parenchymal cells. Earlier work using cancer cell lines concluded that about half of the CP uptake is due to passive diffusion through the plasma membrane and the remaining half is mediated by an unknown transporter (9). Studies have identified two different membrane transporters capable of transporting CP into cells: Ctr1 and OCT2. The Ctr1 is a copper transporter, which was also shown to mediate $\mathrm{CP}$ uptake into mammalian cells (10) including ovarian cancer cells (11). The Ctr1 is highly expressed in adult kidney and the protein is localized to the basolateral membrane of the proximal tubule. In vitro down regulation of Ctr1 expression in kidney cells decreased both CP uptake and cytotoxicity, suggesting that Ctr1 is an important protein in CP uptake in these cells (12).
In addition, the organic cation transporters (OCTs) have been implicated in CP uptake (13). The CP-induced tubular cell injury may be related to basolateral organic cation transport (14). Three isoforms of OCTs are expressed in renal proximal tubules, mainly at the basolateral side (15). Study provided evidence for OCT2 to be the critical OCT responsible for CP uptake in the kidney. They showed that CP uptake was increased by OCT2 overexpression in HEK293 cells, which was associated with increased cellular sensitivity to CP toxicity (16). Consistently, proximal tubular cells isolated from a human diabetic kidney showed reduced CP uptake, which was attributed to the well-documented lower expression of OCT2 in diabetes. Interestingly, CP did not interact with OCT1. It was speculated that because OCT1 is mainly expressed in the liver and OCT2 in the kidneys, this differential expression pattern of OCTs in different tissues might account for organ-specific toxicity of CP. Of note, the less nephrotoxic analogues of CP such as carboplatin and oxaliplatin did not interact with OCT2 (16). Cisplatin was shown to inhibit the uptake of other OCT2 substrates, which is consistent with the view stating these substrates share a common transport pathway. Likewise, cimetidine, an OCT2 substrate, reduced CP uptake and cytotoxicity in vitro (16) and CP-induced nephrotoxicity in vivo (17). Two recent observations point to an important role for OCT2 in mediating renal CP uptake and toxicity. First, knockout of the OCT2 gene significantly reduced urinary $\mathrm{CP}$ excretion (18) and nephrotoxicity $(17,18)$. Second, a no synonymous single-nucleotide polymorphism (SNP) in the OCT2 gene (rs316019) was associated with reduced CP-induced nephrotoxicity (17, 18). Finally, I suggest these differences may be related to CP uptake by OCT2 due to the renal expression of OCT2 was markedly higher in male than was in female rats (19). Therefore, CP uptake was increased by OCT2 overex- 
pression in male rats and was associated with increased cellular sensitivity to CP toxicity.

\section{References}

1. Nematbakhsh M, Ebrahimian S, Tooyserkani M, Eshraghi-Jazi F, Talebi A, Ashrafi F. Gender difference in Cisplatin-induced nephrotoxicity in a rat model: greater intensity of damage in male than female. Nephrourol Mon. 2013;5(3):818-21.

2. Nematbakhsh M, Pezeshki Z, Eshraghi-Jazi F, Ashrafi F, Nasri H, Talebi A, et al. Vitamin E, Vitamin C, or Losartan Is Not Nephroprotectant against Cisplatin-Induced Nephrotoxicity in Presence of Estrogen in Ovariectomized Rat Model. Int J Nephrol. 2012;2012:284896.

3. Carraro-Eduardo JC, Oliveira AV, Carrapatoso ME, Ornellas JF. Effect of sex hormones on gentamicin-induced nephrotoxicity in rats. Braz J Med Biol Res. 1993;26(6):653-62.

4. Pezeshki Z, Nematbakhsh M, Mazaheri S, Eshraghi-Jazi F, Talebi A, Nasri H, et al. Estrogen Abolishes Protective Effect of Erythropoietin against Cisplatin-Induced Nephrotoxicity in Ovariectomized Rats. ISRN Oncol. 2012;2012:890310.

5. Safari T, Nematbakhsh M, Hilliard LM, Evans RG, Denton KM. Sex differences in the renal vascular response to angiotensin II involves the Mas receptor. Acta Physiol (Oxf). 2012;206(2):150-6.

6. Hilliard LM, Nematbakhsh M, Kett MM, Teichman E, Sampson AK Widdop RE, et al. Gender differences in pressure-natriuresis and renal autoregulation: role of the Angiotensin type 2 receptor. $H y$ pertension. 2011;57(2):275-82.

7. Winston JA, Safirstein R. Reduced renal blood flow in early cisplatin-induced acute renal failure in the rat. Am J Physiol. 1985;249(4 Pt 2):F490-6.

8. Yao X, Panichpisal K, Kurtzman N, Nugent K. Cisplatin nephrotoxicity: a review. Am J Med Sci. 2007;334(2):115-24.

9. Gately DP, Howell SB. Cellular accumulation of the anticancer agent cisplatin: a review. BrJ Cancer.1993;67(6):1171-6.

10. Ishida S, Lee J, Thiele DJ, Herskowitz I. Uptake of the anticancer drug cisplatin mediated by the copper transporter Ctr1 in yeast and mammals. Proc Natl Acad Sci US A. 2002;99(22):14298-302.

11. Holzer AK, Samimi G, Katano K, Naerdemann W, Lin X, Safaei R, et al. The copper influx transporter human copper transport protein 1 regulates the uptake of cisplatin in human ovarian carcinoma cells. Mol Pharmacol. 2004;66(4):817-23.

12. Pabla N, Murphy RF, Liu K, Dong Z. The copper transporter Ctr1 contributes to cisplatin uptake by renal tubular cells during cisplatin nephrotoxicity. Am J Physiol Renal Physiol. 2009;296(3):F505-11.

13. Yonezawa A, Masuda S, Nishihara K, Yano I, Katsura T, Inui K. Association between tubular toxicity of cisplatin and expression of organic cation transporter rOCT2 (Slc22a2) in the rat. Biochem Pharmacol. 2005;70(12):1823-31.

14. Ludwig T, Riethmuller C, Gekle M, Schwerdt G, Oberleithner H Nephrotoxicity of platinum complexes is related to basolateral organic cation transport. Kidney Int. 2004;66(1):196-202.

15. Motohashi H, Sakurai Y, Saito H, Masuda S, Urakami Y, Goto M, et al. Gene expression levels and immunolocalization of organic ion transporters in the human kidney. J Am Soc Nephrol. 2002;13(4):866-74.

16. Ciarimboli G, Ludwig T, Lang D, Pavenstadt H, Koepsell H, Piechota HJ, et al. Cisplatin nephrotoxicity is critically mediated via the human organic cation transporter 2. Am J Pathol. 2005;167(6):1477-84.

17. Ciarimboli G, Deuster D, Knief A, Sperling M, Holtkamp M Edemir B, et al. Organic cation transporter 2 mediates cisplatininduced oto- and nephrotoxicity and is a target for protective interventions. Am J Pathol. 2010;176(3):1169-80.

18. Filipski KK, Mathijssen RH, Mikkelsen TS, Schinkel AH, Sparreboom A. Contribution of organic cation transporter 2 (OCT2) to cisplatin-induced nephrotoxicity. Clin Pharmacol Ther 2009;86(4):396-402.

19. Urakami Y, Nakamura N, Takahashi K, Okuda M, Saito H, Hashimoto Y, et al. Gender differences in expression of organic cation transporter OCT2 in rat kidney. FEBS Lett. 1999;461(3):339-42. 